\title{
Equine Coronavirus Infection
}

\author{
Nicola Pusterla, Ron Vin, Christian Leutenegger, \\ Linda D. Mittel, and Thomas J. Divers
}

\subsection{Etiology}

Coronaviruses are members of the Coronaviridae family, all of which are singlestranded, positive-sense, non-segmented, enveloped RNA viruses responsible for enteric, respiratory, hepatic, or neurologic disease in a variety of mammalian and avian species (Wege et al. 1982). The family Coronaviridae is subdivided in two subfamilies, Torovirinae and Coronavirinae, with the latter subfamily containing four genera defined on the basis of serological cross-reactivity and genetic differences: Alphacoronavirus, Betacoronavirus, Deltacoronavirus, and Gammacoronavirus (Woo et al. 2012). Equine coronavirus (ECoV) is classified within the Betacoronavirus genus, along with human OC43 and HKU1 coronavirus, bovine coronavirus, porcine hemagglutinating encephalomyelitis virus, canine respiratory coronavirus, mouse hepatitis virus, and sialodacryoadenitis virus (Zhang et al. 2007).

The nucleocapsid protein of coronaviruses complexes with the genomic RNA to form a helical capsid structure found within the viral envelope. Trimers of the spike protein form peplomers embedded in the envelope giving the virion its corona or

\footnotetext{
N. Pusterla $(\square)$

Department of Medicine and Epidemiology, School of Veterinary Medicine, University of California, Davis, CA 95616, USA

e-mail: npusterla@ucdavis.edu

R. Vin • C. Leutenegger

IDEXX Laboratories, Inc., West Sacramento, CA 95605, USA

L.D. Mittel

The Animal Health Diagnostic Center, College of Veterinary Medicine, Cornell University, Ithaca, NY 14853, USA

T.J. Divers

College of Veterinary Medicine, Cornell University, Ithaca, NY 14853, USA
}

J. Bayry (ed.), Emerging and Re-emerging Infectious Diseases of Livestock, 
crown-like morphology. In ECoV, the hemagglutinin-esterase protein forms smaller spikes on the membrane. There are two fully transmembraneous structural proteins referred to as the membrane and small membrane proteins in the coronavirus virion (Weiss and Leibowitz 2011).

\subsection{Epidemiology}

Epidemiological information for $\mathrm{ECoV}$ is sparse at this time and either extrapolated from close-related coronaviruses such as $\mathrm{BCoV}$ or largely based on non-published preliminary observations (Table 4.1).

Clinical cases are either sporadic or epizootic. Collective data from three veterinary diagnostic laboratories in the USA (IDEXX Laboratories, Inc., West Sacramento; Animal Health Diagnostic Center (AHDC), Cornell University, Ithaca; Real-time PCR Research and Diagnostics Core Facility, University of California, Davis) shows that the overall number of ECoV qPCR-positive cases is steadily

Table 4.1 Documented or observed epidemiological factors for BCoV and ECoV (Pusterla et al. 2015a)

\begin{tabular}{|c|c|c|}
\hline $\begin{array}{l}\text { Epidemiological } \\
\text { factors }\end{array}$ & BCoV (winter dysentery) & $\mathrm{ECoV}$ \\
\hline Case presentation & Epizootic & Sporadic and epizootic \\
\hline $\begin{array}{l}\text { Age of affected } \\
\text { animals }\end{array}$ & Predominantly cattle & Predominantly adult horses \\
\hline Seasonality & $\begin{array}{l}\text { Usually during winter month } \\
\text { (November to April) }\end{array}$ & $\begin{array}{l}\text { Year around with increased reports } \\
\text { during cold months (October to } \\
\text { April) }\end{array}$ \\
\hline Transmission route & Feco-oral & $\begin{array}{l}\text { Suspected feco-oral for natural } \\
\text { disease, naso-esophageal for } \\
\text { experimental disease }\end{array}$ \\
\hline $\begin{array}{l}\text { Geographic } \\
\text { distribution }\end{array}$ & More common in northern states & No geographic predilection \\
\hline Morbidity rate & High $(30-100 \%)$ & Variable $(10-80 \%)$ \\
\hline Mortality rate & Rare & Low \\
\hline Incubation time & $2-8$ days & $2-3$ days \\
\hline Outbreak duration & Less than 2 weeks & $2-3$ weeks \\
\hline Period of illness & Few days to 1 week & Few days to 1 week \\
\hline Clinical signs & $\begin{array}{l}\text { Explosive diarrhea, anorexia, } \\
\text { depression, reduced milk } \\
\text { production }\end{array}$ & $\begin{array}{l}\text { Anorexia, depression, fever, less } \\
\text { frequently diarrhea, colic, } \\
\text { neurological signs }\end{array}$ \\
\hline Diagnosis & $\begin{array}{l}\text { Antigen-capture ELISA, } \\
\text { fluorescent antibody, qPCR, } \\
\text { electron microscopy }\end{array}$ & qPCR \\
\hline Recovery & $\begin{array}{l}\text { Fast, generally self-limiting } \\
\text { disease }\end{array}$ & Fast, generally self-limiting disease \\
\hline Prevention & Vaccination and biosecurity & Biosecurity \\
\hline
\end{tabular}


increasing since 2010 (approximate time when ECoV testing by qPCR was introduced by molecular diagnostic laboratories) and that similar to $\mathrm{BCoV}$, the case number is higher during the colder months of the year (October to April). Clinical ECoV infection has predominantly been reported in adult horses (Oue et al. 2011, 2013; Pusterla et al. 2013; Fielding et al. 2015). Outbreaks have been reported in riding, racing, and show horses and less frequently in breeding animals. One hypothesis, behind the lack of large numbers of documented clinical cases at larger breeding farms, is the frequent circulation of ECoV between asymptomatic young animals and adult resident horses, conferring protection against clinical disease in adult horses.

Preliminary epidemiological observations support a feco-oral route of transmission. This is supported by a recent experimental study in which three 9-to-10-month old Japanese draft horses were successfully infected via naso-esophageal intubation using fecal material from a previously characterized ECoV-infected horse (Nemoto et al. 2014). Two out of the three draft horses developed clinical disease, and all of them shed large amounts of ECoV in feces. Bovine coronavirus (BCoV) is closely related to $\mathrm{ECoV}$ and considered a pneumoenteric virus, causing not only enteric disease but also mild upper respiratory signs (Saif et al. 1986; Tsunemitsu et al. 1999; Tråvén et al. 2001; O’Neill et al. 2014). Recently, a French group screened 395 feces and 200 respiratory specimens submitted to a veterinary diagnostic laboratory for the presence of ECoV (Miszczak et al. 2014). The samples had been collected from foals and adult horses suffering from mild respiratory or enteric disease. In that study, the researchers found ECoV by qPCR in a total of 12 samples ( 11 fecal samples and one respiratory specimen). In a study testing nasal secretions from 2437 horses with signs of fever and/or acute onset of upper respiratory tract infection submitted to a commercial diagnostic laboratory in the USA from January 2013 to December 2014 for the detection of common respiratory pathogens, ECoV was detected by qPCR in only 17 (0.7 \%) horses (Pusterla et al. 2015b). Collectively, both these studies show that ECoV is infrequently detected in nasal secretions from horses with infectious upper respiratory tract disease, suggesting lack of tropism for ECoV to the respiratory epithelium. In the three experimentally infected Japanese draft horses (Nemoto et al. 2014), nasal secretions were ECoV PCR positive during the time of peak fecal shedding, but it could not be determined if this was due to nasal replication and shedding of the virus or from environmental contamination from the positive feces or both.

Morbidity of ECoV in affected herds is variable and has been reported to range between 10 and $83 \%$ (Oue et al. 2011, 2013; Pusterla et al. 2013; Fielding et al. 2015). Mortality rates have been reported to be low (Oue et al. 2011, 2013; Pusterla et al. 2013), although a mortality rate of $27 \%$ was recently reported by Fielding et al. (2015) in American miniature horses. Mortality has been associated with endotoxemia, septicemia, and hyperammonemia-associated encephalopathy (Pusterla et al. 2013; Fielding et al. 2015; Giannitti et al. 2015). A large number of documented clinical cases will be needed to determine the effect of various host, viral, treatment, and environmental factors on outcome, as well as the identification of risk factors associated with risk of morbidity. 
Similar to BCoV the incubation period is short, and clinical disease develops between 48 and $72 \mathrm{~h}$ after either natural exposure or experimental infection (Nemoto et al. 2014; Fielding et al. 2015). Clinical signs persist for a few days to 1 week and generally resolve with minimal supportive care. Occasionally, clinical signs can last longer as recently identified in two ECoV cases from Florida that experienced colic and systemic illness for 14 days (Mittel personal communication 2016). Shedding post-experimental infection as documented by qPCR ranged between 10 and 12 days (Nemoto et al. 2014). Fecal shedding of ECoV under natural conditions has been reported to range between three and 25 days (Pusterla et al. 2013; Fielding et al. 2015; Mittel personal communication 2016). It is not clear how long ECoV will persist in the environment and potentially act as the source of infection. It is reasonable to draw comparisons from other coronaviral pathogens such as severe acute respiratory syndrome-associated coronavirus (SARS-CoV) which has been shown in vitro to persist for 2 days in hospital wastewater, domestic sewage, and dechlorinated tap water while 3 days in feces, 14 days in PBS, and 17 days in urine at $20{ }^{\circ} \mathrm{C}$. However, at $4{ }^{\circ} \mathrm{C}$, the SARS-CoV could persist for 14 days in wastewater and at least 17 days in feces or urine (Wang et al. 2005). Enhanced replication of the virus in feces in the environment during colder weather is one possible explanation for the apparent higher prevalence of test-positive fecal samples and clinical disease during cooler weather. $\mathrm{ECoV}$ disease can occur in one or more horses on a farm with no recent exposure to new horses (divers, personal communication 2016). Hypothetically this might be explained by indirect ECoV transmission by non-equine animal species or that colder weather might allow increased fecal replication of the virus from a chronically infected horse.

\subsection{Clinical Presentation}

Clinical information collected from 16 outbreaks during the time period of November 2011 to December 2014 on a total of 406 horses showed that 122 horses (30 \%) showed clinical signs (Pusterla et al. 2013; Pusterla, personal communication 2016). The main clinical signs reported were anorexia (98\%), lethargy (89\%), and fever $(84 \%)$. The rectal temperature of febrile horses ranged from 38.6 to $41.0^{\circ} \mathrm{C}$ (median $39.9^{\circ} \mathrm{C}$ ). Changes in fecal character, ranging from soft formed to watery consistency (Fig. 4.1), and colic were observed in $25 \%$ and $18 \%$ of horses with any clinical signs, respectively. Gastrointestinal signs are generally preceded by systemic signs of anorexia and fever (Fig. 4.2). These results are in agreement with recent outbreaks from Japan in adult draft horses reporting that anorexia and pyrexia were the main clinical signs, while specific gastrointestinal signs were observed in about $10 \%$ of affected horses (Oue et al. 2011, 2013). In $3 \%$ of infected horses, signs of encephalopathy including circling, head pressing, ataxia, proprioceptive deficits, nystagmus, recumbency, and seizure have also been reported (Fig. 4.3; Pusterla et al. 2013; Fielding et al. 2015). 


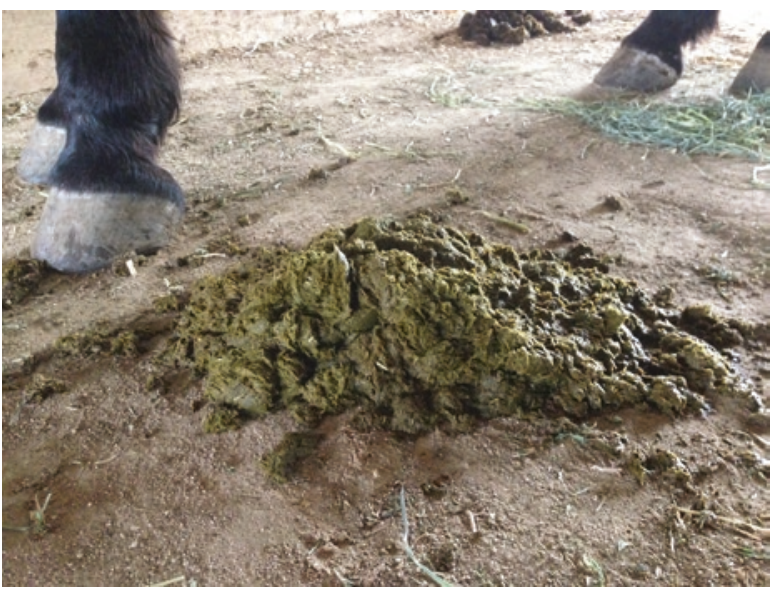

Fig. 4.1 Soft-formed feces from a horse with clinical ECoV infection and concurrent depression, anorexia, and fever

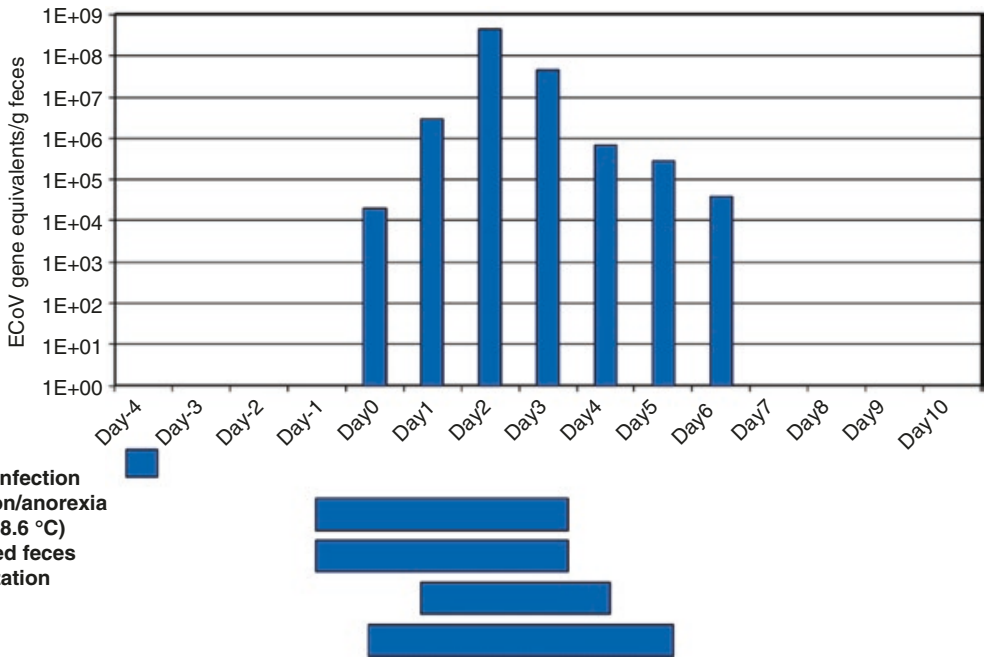

Fig. 4.2 Diagram showing temporal clinical signs and fecal shedding of ECoV in an adult horse presented to a referring hospital (day 0 was the first day of hospitalization) because of anorexia, depression, and fever

Although clinical disease is apparent in 10-83 \% of ECoV-infected horses, one needs to take into account that some horses remain asymptomatic after infection. Asymptomatic infection is defined as lack of clinical disease in a horse from which $\mathrm{ECoV}$ is detected in feces by qPCR. The percentage of asymptomatic horses during an outbreak of ECoV has been observed to range between 11 and $83 \%$ (Pusterla et al. 2013). 
Fig. 4.3 Head pressing in an adult thoroughbred gelding with clinical ECoV infection

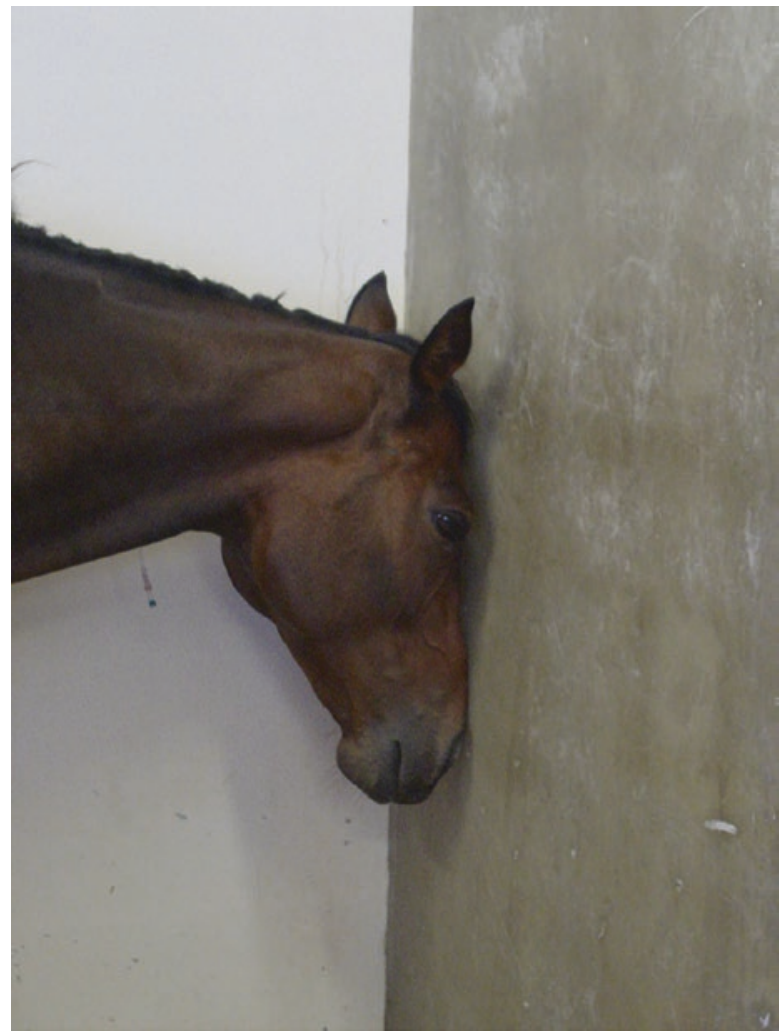

\subsection{Diagnostic Evaluation}

The antemortem diagnosis of ECoV relies on the presence of clinical signs compatible with ECoV infection, neutropenia, and/or lymphopenia, the exclusion of other infectious causes, and the molecular detection of ECoV in feces.

The consistently observed hematological abnormalities with ECoV infection are leukopenia due to neutropenia and/or lymphopenia. The blood work from 73 clinical cases with suspected ECoV infection showed that the total nucleated cell count ranged from 520 to $7800 / \mu 1$ (median 3580/ $\mu$ l; reference interval 5000-11,600/ $\mu$; Fig. 4.4). The white cell blood count in the 73 diseased horses showed leukopenia in $25 \%$, neutrophilia in $66 \%$, and lymphopenia in $72 \%$ of the horses. The neutrophil and lymphocyte counts in these horses ranged from 180 to $5070 / \mu 1$ (median $1650 / \mu \mathrm{l}$; reference interval 2600-6800/ $\mu \mathrm{l}$ ) and 80-3580/ $\mu \mathrm{l}$ (median 1090/ $\mu \mathrm{l}$; reference interval 1600-5800/ $\mu$ l), respectively. Both the complete blood count (CBC) and white cell differential were unremarkable in only $11 \%$ of the horses. Additionally, less consistent hematological abnormalities included the presence of band neutrophils and shifts in monocyte counts (most typically shifting from a low or a normal count to a high normal or rebound monocytosis). Occasional rebound 
Fig. 4.4 Hematological findings in 73 adult horses with laboratory confirmation of ECoV infection. The results are expressed as box and whiskers (Reproduced from Pusterla et al. 2015a)

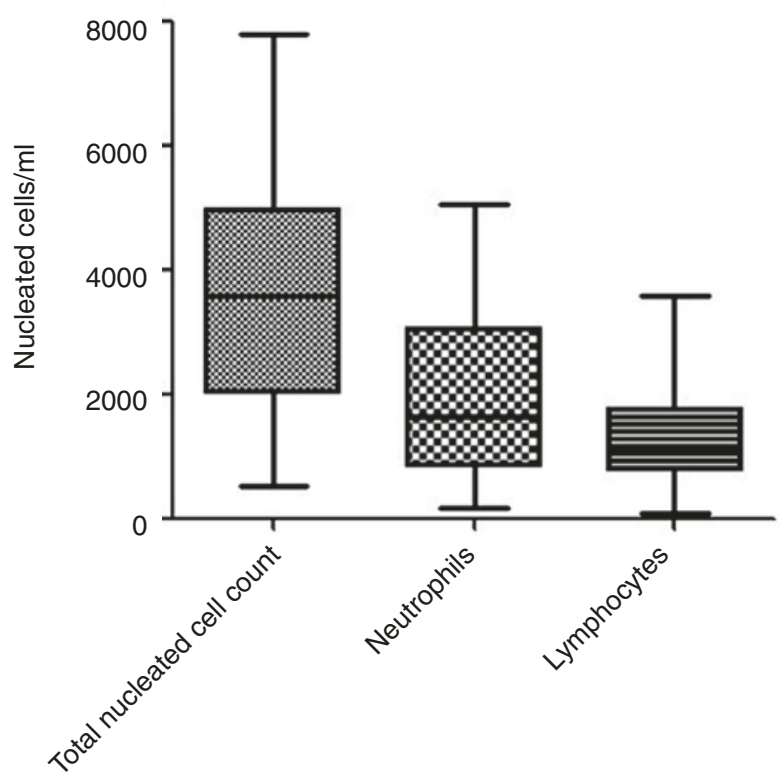

leukocytosis due to neutrophilia and monocytosis during the disease course and recovery was observed as well. $\mathrm{CBC}$ abnormalities are expected to resolve within 5-7 days as long as no complications associated with the disruption of the gastrointestinal barrier occur. Biochemical parameters may be unremarkable, but elevation of total and indirect bilirubin due to partial or complete anorexia, electrolyte changes consistent with enterocolitis, transient elevation of liver enzymes, and renal parameters suggestive of prerenal azotemia have been observed in some of the cases. It is judicious to measure blood ammonia in horses with suspected ECoV infection and concurrent signs of encephalopathy. Fielding et al. (2015) reported on a case of severe hyperammonemia $(677 \mu \mathrm{mol} / \mathrm{L}$; reference interval $\leq 60 \mu \mathrm{mol} / \mathrm{L})$ with encephalopathic signs that subsequently died. Hyperammonemia associated with ECoV infection is likely due to increased ammonia production within or absorption from the gastrointestinal tract due to gastrointestinal barrier breakdown. An increase in enteric ammonia production could also be the result of bacterial microbiome changes associated with EcoV infection.

Isolation of ECoV in human rectal adenocarcinoma cells, although difficult, has been previously reported (Guy et al. 2000; Oue et al. 2011). The need for costeffective and timely detection methods has restricted the diagnosis of ECoV infection to direct demonstration of coronavirus antigens or specific nucleic acids in biological samples. Historically, coronavirus detection in feces had been based on negative-stain EM and antigen-capture ELISA (Davis et al. 2000; Guy et al. 2000). However, the sensitivity and specificity of these diagnostic modalities have not been evaluated, and detection may be unsuccessful if viral particles are not present in sufficient numbers. Sensitive laboratory diagnosis of ECoV is through fecal 
quantitative PCR (qPCR). A recent study evaluated the overall accuracy of qPCR and determined $90 \%$ accuracy between clinical status and PCR detection of ECoV in various outbreak populations (Pusterla et al. 2013). The authors have documented a few cases of ECoV infection, which tested qPCR negative during early disease. These few horses ended testing qPCR positive on a $24-48 \mathrm{~h}$ recheck fecal sample. It is hypothesized that during peracute stages of infection or when diseased horses experience gastrointestinal stasis due to colic, there are not enough viral particles in the feces to be detected. The recommendation is to retest fecal matter in a suspected index case at a later time point or collect multiple samples for pooled testing. Viral kinetics of ECoV in feces from experimentally infected horses showed that horses began to shed ECoV RNA in their feces at 3 or 4 days postinfection and continued shedding virus until 12 or 14 days postinfection (Nemoto et al. 2014). Peak shedding is generally seen on day 3 to 4 following the development of clinical signs (Fig. 4.2), and qPCR detection of ECoV in naturally infected horses can last for 3-25 days (Pusterla et al. 2013; Fielding et al. 2015).

Interestingly, the fecal viral load measured by qPCR in foals (up to 6 months) appears to be lower compared to horses older than 12 months of age, although the difference is not statistically significant $(P=0.307)$. This observation suggests that viral replication in the gut is comparable (Leutenegger, personal communication 2016) between foals and older horses. In human coronavirus infections, viral load is a strong prognostic indicator for clinical outcome and mortality (Hung et al. 2009). A similar observation has recently been reported for ECoV (Fielding et al. 2015). The viral load that is shed in humans infected with coronavirus is associated with polymorphisms of genes involved in innate immunity, an individual's genetic makeup, and immunologic host response to the virus (Chen et al. 2006). In addition, coronavirus strain variations can influence the replication ability and viral load as shown with feline coronavirus $(\mathrm{FCoV})$ which exists in two genotypes: a benign feline enteric coronavirus genotype (FECV) with low replication competency in enterocytes and a highly virulent feline infectious peritonitis virus (FIPV) with an enhanced ability to replicate in different cell populations (Chang et al. 2012). Single-point mutations on the spike gene are responsible for dramatic changes in cell tropism, replication competency, and clinical manifestations.

Necropsy cases of suspected enteritis should have feces or gastrointestinal content tested by qPCR for ECoV and other gastrointestinal infectious agents. Further, formalin-fixed intestinal tissue samples can also be tested by immunochemistry and direct fluorescent antibody testing using BCoV reagents (Giannitti et al. 2015).

\subsection{Pathogenesis}

Enteritis caused by ECoV has been suspected in foals for many years, but the direct pathogenicity of ECoV has only been described in one neonate (Davis et al. 2000). Further, the high and similar frequency of ECoV shedding detected in healthy foals and foals with gastrointestinal diseases from Central Kentucky suggests that ECoV commonly circulates among young horses with subclinical disease (Slovis et al. 2014). 
An interesting observation is that all ECoV infections in foals with gastrointestinal disease were associated with coinfections, while most healthy foals infected with ECoV displayed a mono-infection (Slovis et al. 2014). This observation may indicate that in foals, pre-existing ECoV infection may predispose to opportunistic secondary viral, bacterial, or protozoal infections as shown for enteric and respiratory coronavirus in other species (Pakpinyo et al. 2003; Srikumaran et al. 2007; Brockmeier et al. 2008). Other hypothetical reasons for the lack of clinical signs in foals infected solely with $\mathrm{ECoV}$ are that host factors such as the absence of specific receptor binding sites or presence of ECoV-specific colostrally derived antibodies prevent the development of enteritis. However, in the vast majority of clinical adult horses, ECoV is a mono-infection, demonstrated by enteric panel qPCR testing. This suggests a unique pathogenicity, coinfection with still unknown pathogens, or a distinct difference in immunological reaction between foals and adult horses toward the ECoV infection similar to FCoV. The development of a humoral, cell-mediated, or mixed immune response against the highly virulent FIPV version of FCoV distinctly influences the clinical outcome of the infection. Interestingly, the clinical outcome of FIPV has been correlated with a severe suppression of NK cells and T regulatory cells confirming earlier reports that a weakened cell-mediated immune response is associated with fatal FIPV infection (Vermeulen et al. 2013).

In adult horses, the pathology of ECoV has recently been described in three equids (Giannitti et al. 2015). The ECoV-infected equids displayed severe diffuse necrotizing enteritis with marked villus attenuation, epithelial cell necrosis in the tips of the villi, neutrophilic and fibrin extravasation into the small intestinal lumen (pseudomembrane formation), as well as crypt necrosis, microthrombosis, and hemorrhage (Fig. 4.5). ECoV was detected by qPCR in small intestinal tissue, gastrointestinal content, and/or feces, and coronavirus antigen was detected by immunohistochemistry and/or direct fluorescent antibody testing in the small intestine of all cases (Fig. 4.6).

\subsection{Treatment and Prevention}

Most adult horses with clinical ECoV infection recover spontaneously in a few days without specific treatment. Horses with persistent elevated rectal temperature, anorexia, and depression are routinely treated with nonsteroidal anti-inflammatory drugs such as flunixin meglumine $(0.5-1.1 \mathrm{mg} / \mathrm{kg}$ BWT q12-24 h IV or PO) or phenylbutazone (2-4 mg/kg BWT q12-24 h IV or PO) for 24-48 h, as long as their hydration status is believed normal. Horses with colic, persistent depression, and anorexia and/or diarrhea have been treated more intensively with fluid and electrolyte per nasogastric intubation or intravenous administration of polyionic fluids until clinical signs have resolved. Additionally, antimicrobials and gastrointestinal protectants should be considered in horses developing signs of endotoxemia and/or septicemia secondary to disruption of the gastrointestinal barrier. While hyperammonemia-associated encephalopathy only occurs in a small percentage of horses with ECoV infection, early recognition and treatment is associated with a 


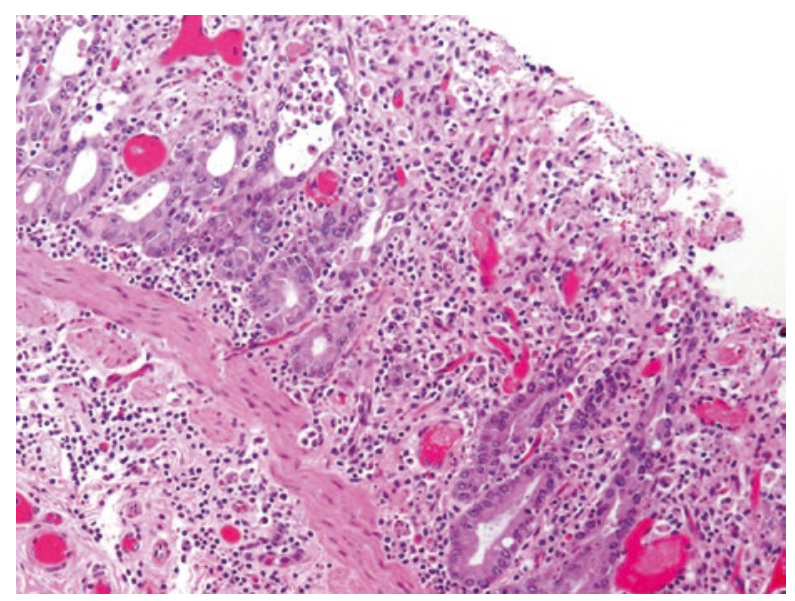

Fig. 4.5 H\&E stain of jejunum from an adult horse with ECoV infection. There is loss of crypts and few remaining crypts are dilated, lined by attenuated epithelium, and contain sloughed necrotic enterocytes. The lamina propria and superficial submucosa are expanded by inflammatory infiltrates. Capillaries and venules in the mucosa and submucosa are occluded by fibrin thrombi (Reproduced from Pusterla et al. 2015a)

Fig. 4.6 Bovine

coronavirus

immunohistochemistry and hematoxylin counterstain of jejunum from an adult horse with $\mathrm{ECoV}$ infection. Strong granular/globular immunoreactivity is seen in the cytoplasm of deep gland enterocytes (Reproduced from Pusterla et al. 2015a)

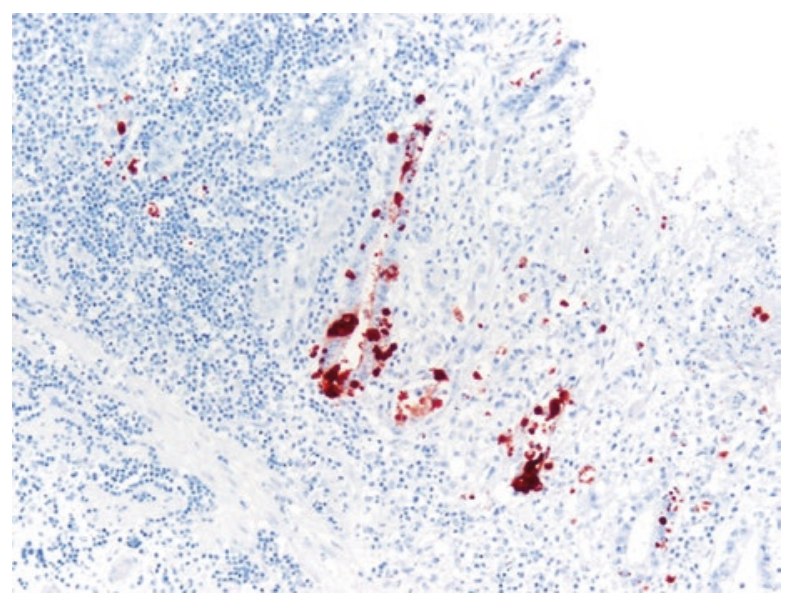

positive outcome. Horses with suspected or documented hyperammonemia are treated with oral lactulose $(0.1-0.2 \mathrm{ml} / \mathrm{kg}$ BWT q6-q12 h PO), neomycin sulfate (4-8 mg/kg BWT q8 h PO), or fecal transfaunation and crystalloid fluids.

Immunization strategies have been best described in cattle for the prevention of winter dysentery infection using a modified-live commercially available BCoV vaccine (Welter 1998). The use of BCoV vaccine in horses for the prevention of ECoV has to the author's knowledge not been investigated and cannot be recommended at this time due to the lack of safety and efficacy data and sporadic incidence of disease. Cattle that recovered from winter dysentery after experimental infection with 
BCoV maintained a very long-lasting BCoV-specific serum (IgA and IgG) and local (IgA) antibody response (Tråvén et al. 2001).

\subsection{Biosecurity Recommendations}

The prevention of ECoV infection should focus on the implementation of routine management practices aimed at reducing the likelihood of introducing and disseminating ECoV at any horse-based premise (boarding facility, showground, veterinary hospital). Due to the highly contagious nature of ECoV, any horse developing or presenting with significant fever, anorexia, and depression with or without enteric signs (colic, diarrhea) should be strictly isolated until a diagnosis is secured. Such an approach can prevent the quarantine of an entire horse population should ECoV infection be diagnosed subsequently. Once ECoV infection is confirmed, strict isolation procedures and secondary quarantine of the source stable of the particular horse should be employed. Postinfection testing of clinical cases should be done to prevent viral spread to other horses. At stables and farms, all newly arrived horses should ideally be isolated for at least 3 weeks. Once an ECoV infection is suspected or confirmed, strict biosecurity measures including footbaths and the use of personal protective equipment should be provided and adequately maintained for sanitary purposes. Separate equipment, tack, bedding, and feedstuffs should be used in the care of these animals. Grooms and other personnel should be instructed to work with these animals last in the course of their daily routine. Exercise periods should be confined to a time when other horses are not present in the training areas, and riders should wear protective clothing and clean and thoroughly disinfect their boots, tack, and hands after contact with such animals. Horses returning from shows or extended traveling events should be isolated according to their particular circumstances. All horse vans and trailers should be thoroughly cleaned and disinfected after use. Equine coronavirus is susceptible to common disinfectants including sodium hypochlorite, povidone-iodine, chlorhexidine gluconate, phenols, quaternary ammonium compounds, accelerated hydrogen peroxide, and peroxygen compounds. The examination of at-risk horses for clinical signs of disease, including twice daily assessment of rectal temperature, remains the most effective tool in determining possible sources of virus introduction.

\section{References}

Brockmeier SL, Loving CL, Nicholson TL et al (2008) Coinfection of pigs with porcine respiratory coronavirus and Bordetella bronchiseptica. Vet Microbiol 128:36-47

Chang H, Egberink HF, Halpin R et al (2012) Spike protein fusion peptide and feline coronavirus virulence. Emerg Infect Dis 18:1089-1095

Chen W, Yang J, Lin J et al (2006) Nasopharyngeal shedding of severe acute respiratory syndromeassociated coronavirus is associated with genetic polymorphisms. Clin Infect Dis 42:1561-1569

Davis E, Rush BR, Cox J et al (2000) Neonatal enterocolitis associated with coronavirus infection in a foal: a case report. J Vet Diagn Investig 12:153-156

Fielding CL, Higgins JK, Higgins JC et al (2015) Disease associated with equine coronavirus infection and high case fatality rate. J Vet Intern Med 29:307-310 
Giannitti F, Diab S, Mete A et al (2015) Necrotizing enteritisi and hyperammonemic encephalopathy associated with equine coronavirus infection in equids. Vet Pathol 52:1148-1156

Guy JS, Breslin JJ, Breuhaus B et al (2000) Characterization of a coronavirus isolated from a diarrheic foal. J Clin Microbiol 38:4523-4526

Hung IF, Lau SK, Woo PC et al (2009) Viral loads in clinical specimens and SARS manifestations. Hong Kong Med J 15:20-22

Miszczak F, Tesson V, Kin N et al (2014) First detection of equine coronavirus (ECoV) in Europe. Vet Microbiol 171:206-209

Nemoto M, Oue Y, Morita Y et al (2014) Experimental inoculation of equine coronavirus into Japanese draft horses. Arch Virol 159:3329-3334

O'Neill R, Mooney J, Connaghan E (2014) Patterns of detection of respiratory viruses in nasal swabs from calves in Ireland: a retrospective study. Vet Rec 175:351

Oue Y, Ishihara R, Edamatsu $\mathrm{H}$ et al (2011) Isolation of an equine coronavirus from adult horses with pyrogenic and enteric disease and its antigenic and genomic characterization in comparison with the NC99 strain. Vet Microbiol 150:41-48

Oue Y, Morita Y, Kondo T et al (2013) Epidemic of equine coronavirus at Obihiro Racecourse, Hokkaido, Japan in 2012. J Vet Med Sci 75:1261-1265

Pakpinyo S, Ley DH, Barnes HJ et al (2003) Enhancement of enteropathogenic Escherichia coli pathogenicity in young turkeys by concurrent turkey coronavirus infection. Avian Dis 47:396-405

Pusterla N, Mapes S, Wademan C et al (2013) Emerging outbreaks associated with equine coronavirus in adult horses. Vet Microbiol 162:228-231

Pusterla N, Vin R, Leutenegger C et al (2015a) Equine coronavirus: an emerging enteric virus of adult horses. Equine Vet Educ. doi:10.1111/eve.12453

Pusterla N, Holzenkaempfer N, Mapes S et al (2015b) Prevalence of equine coronavirus in nasal secretions from horses with fever and upper respiratory tract infection. Vet Rec. doi:10.1136/ vr.103263

Saif LJ, Redman DR, Moorhead PD et al (1986) Experimentally induced coronavirus infections in calves: viral replication in the respiratory and intestinal tracts. Am J Vet Res 47:1426-1432

Slovis NM, Elam J, Estrada M et al (2014) Infectious agents associated with diarrhoea in neonatal foals in central Kentucky: a comprehensive molecular study. Equine Vet J 46:311-316

Srikumaran S, Kelling CL, Ambagala A (2007) Immune evasion by pathogens of bovine respiratory disease complex. Anim Health Res Rev 8:215-229

Tråvén M, Näslund K, Linde N et al (2001) Experimental reproduction of winter dysentery in lactating cows using BCV - comparison with BCV infection in milk-fed calves. Vet Microbiol 81:127-151

Tsunemitsu H, Smith DR, Saif LJ (1999) Experimental inoculation of adult dairy cows with bovine coronavirus and detection of coronavirus in feces by RT-PCR. Arch Virol 144:167-175

Vermeulen BL, Devriendt B, Olyslaegers DA et al (2013) Suppression of NK cells and regulatory $\mathrm{T}$ lymphocytes in cats naturally infected with feline infectious peritonitis virus. Vet Microbiol $164: 46-59$

Wang XW, Li JS, Jin M et al (2005) Study on the resistance of severe acute respiratory syndromeassociated coronavirus. J Virol Methods 126:171-177

Wege H, Siddell S, Ter Meulen V (1982) The biology and pathogenesis of coronavirus. Curr Top Microbiol Immunol 99:165-200

Weiss SR, Leibowitz JL (2011) Coronavirus pathogenesis. Adv Virus Res 81:85-164

Woo PC, Lau SK, Lam CS et al (2012) Discovery of seven novel mammalian and avian coronaviruses in the genus Deltacoronavirus supports bat coronaviruses as the gene source of Alphacoronavirus and Betacoronavirus and avian coronaviruses as the gene source of Gammacoronavirus and Deltacoronavirus. J Virol 86:3995-4008

Welter MW (1998) Adaptation and serial passage of bovine coronavirus in an established diploid swine testicular cell line and subsequent development of a modified live vaccine. Adv Exp Med Biol 440:707-711

Zhang J, Guy JS, Snijder EJ et al (2007) Genomic characterization of equine coronavirus. Virology 369:92-104 